\title{
Does Corticosteroids Administration after 37 Weeks for Elective Lower Segment Cesarean Section Reduce Neonatal Respiratory Morbidity? a Randomized Controlled Trial
}

\begin{abstract}
Department of Obstetrics and Gynecology, Benha faculty of medicine, Benha University, Egypt. b Department of Obstetrics and Gynecology, Benha Teaching Hospital, Benha, Egypt.

Correspondence to: Sally A. Al Saber, Department of Obstetrics and Gynecology, Benha

Teaching Hospital, Benha, Egypt

Email:
\end{abstract}

Ahmed M. Elewa ${ }^{a}$, Ahmed S. Saad ${ }^{\text {a }}$, Ahmed S. Soliman ${ }^{a}$, Sally A. Al Saber ${ }^{b}$

mrbeko36@gmail.com

Received:23 October 2019

Accepted:28 June 2020

\begin{abstract}
:
Background: Cesarean delivery is a known risk factor for neonatal respiratory complications, mostly transient tachypnea of the newborn (TTN) and respiratory distress syndrome (RDS) in infants at or near term. The current study aimed to assess the efficacy of steroids administered before performing term (3739 weeks), elective caesarean section in reducing neonatal respiratory morbidity and. Methods: This is a randomized controlled study which was done on Benha University Hospital and Benha Teaching Hospital, Egypt. Four hundred cases were divided into two groups. Group A (Steroid Group): included 200 cases who received two intramuscular (IM) doses of $12 \mathrm{mg}$ dexamethasone 12 hours apart, 24 hours before elective CS. Group B (Control Group): included 200 cases who received IM saline as a placebo in the same regimen as the steroid group. Results: There was no statistically significant difference between group A and group B regarding maternal age, BMI, gravidity, mean number of previous C.S. birth weight and gestational age. Mean value of Apgar scores at 1 and 5 minutes
\end{abstract} was statistically significant higher among group A than group B.TTN was statistically significant lower among group A than group B. Admission to NICU was statistically significant lower among group A than group B. There was statistically significant higher numbers of neonates in group $\mathrm{A}$ than in group B regarding neonatal need for CPAP. Conclusion : Prophylactic intramuscular injection of $12 \mathrm{mg}$ dexamethasone 12 hours apart, 24 hours before elective CS at gestational age of 37 to 39 weeks can reduce neonatal respiratory morbidity

Key words: Steroids - Elective caesarean section -respiratory morbidity 


\section{Introduction:}

Cesarean delivery is a known risk factor for neonatal respiratory complications, mostly transient tachypnea of the newborn (TTN) and respiratory distress syndrome (RDS) in infants at or near term. The respiratory morbidities may be severe and even fatal ${ }^{(1)}$.

Infants born at term by cesarean delivery are more likely to develop respiratory morbidity than infants born vaginally. The risk increases additionally for neonates born after elective cesarean delivery and if delivery is before 39 weeks. The risk of respiratory morbidities decreases from $3.9 \%$ for the period between 37 weeks to 37 weeks and 6 days to $0.8 \%$ for the period between 39 weeks to 39 weeks and 6 days. Therefore, it has been recommended that elective cesarean delivery should be deferred to 39 weeks $^{(2)}$.

There are other confounding factors that contribute to the development of neonatal respiratory complications following cesarean delivery including the type of anesthesia, fetal weight and antenatal maternal disorders ${ }^{(3)}$.

Respiratory distress syndrome (RDS) is the principal cause of early neonatal morbidity and mortality and significantly contributes to high costs of neonatal intensive care. ${ }^{(4)}$

Elective CS compared with intended vaginal delivery (VD) leads to a two to four-folds increased risk of overall neonatal respiratory morbidity ${ }^{(2)}$

Maternal steroid treatment before preterm delivery is one of the best documented and most cost-effective and life-saving treatments in prenatal medicine ${ }^{(5)}$.

No serious side effects have been reported after administration of corticosteroids during pregnancy, but some studies reported a reduction in fetal body movements, fetal breathing movements and heart rate variation after betamethasone $\operatorname{administration}^{(1)}$.

Antenatal corticosteroids may lead to a reduction in morbidity in babies delivered by $\mathrm{CS}$ at term. However, the evidence for the administration of corticosteroids after 37 weeks is still controversial. Betamethasone given before elective CS at term reduces respiratory distress and admission to pediatric care units ${ }^{(6)}$.

This is of great importance for developing countries where resources are scarce and it is often difficult to provide expensive treatments such as neonatal care ${ }^{(1)}$.

Based on high-grade evidence, antenatal corticosteroid therapy is very effective in preventing neonatal respiratory mortality and morbidity, yet remains at low coverage in low/middle-income countries ${ }^{(7)}$. 
The use of antenatal corticosteroids at or near term may prevent neonatal respiratory complications by various mechanisms. They may act by promoting the molecular mechanisms that allow alveolar fluid drainage. This might be a predominantly lung epithelial sodium channels mechanism. Antenatal corticosteroids may also increase the responsiveness to catecholamines and thyroid hormones. The likely benefits of antenatal steroids should be compared with those of delaying caesarean section until 39 weeks when possible ${ }^{(8)}$.

The current study aimed to assess the efficacy of IM steroids administered before performing term (37-39 weeks), elective caesarean section in reducing both neonatal respiratory morbidity and admission to Neonatal Intensive Care Unit.

\section{Patients and Methods}

\section{Patients:}

Type of study: Randomized controlled comparative study.

Study settings: Benha University Hospital and Benha Teaching Hospital, Egypt.

Study duration: from March 2018 to September 2019.

Ethical considerations: Approval of the Research and Ethics Committee of the Faculty of Medicine, Benha University was taken.
Study population:

Four hundred cases were recruited among those attending Obstetric Departments of both hospitals. They were destined to have an elective LSCS. They were divided into two groups. Group A (Steroid Group): included 200 cases who received two intramuscular doses of $12 \mathrm{mg}$ dexamethasone 12 hours apart, 24 hours before elective CS. Group B (Control group): included 200 cases who received IM saline as a placebo in the same regimen as the steroid group.

The inclusion criteria:

Age: $18-40$ years, gestational age of 37 to 39 weeks, primigravida or multipara, singleton pregnancy. Time of termination was determined before 39 weeks of gestation due to an absolute obstetric indications e.g. (term rupture of membranes, non-reassuring CTG, sonographic features as oligohydramnios, abnormal Doppler indices and bad obstetric history) and repeated CS.

The exclusion criteria:

Fetuses with major congenital anomalies, medical problems that can affect fetal wellbeing, medical or obstetric conditions that warrant early or immediate delivery. Also, women who had received prophylactic Dexamethasone during the current pregnancy and those who developed a 
spontaneous labour were excluded from the study.

Methodology:

1- A detailed history included: Personal history, obstetric history, menstrual history, past and present history of illness.

2- Routine antenatal investigations were reviewed and ordered if not done before.

3- Examination (general, obstetrics and possible local examination)

4- U/S. was done for all patients and other aids as CTG and possible fetal Doppler indices.

5-An informed consent was signed by the study group population after randomization.

Cases in Group A received two intramuscular doses of $12 \mathrm{mg}$ Dexamethasone (Sigma Co, Cairo, Egypt), separated by $12 \mathrm{~h}$ apart at 37 weeks or beyond, $24 \mathrm{hrs}$ before elective CS.

Group B received IM saline as a placebo in the same regimen as the steroid group.

Caesarean delivery was done by an experienced obstetrician (A specialist or assistant lecturer) in the usual manner under spinal anesthesia according to departmental protocol.

\section{Outcome Measures}

- Gestational age at birth was defined as completed weeks of gestation on the basis of the estimated date of delivery in each woman's clinical record. Gestational age was confirmed by ultrasonographic examination in the first half of pregnancy.

- The inquired neonatal respiratory morbidity included any respiratory distress, transient tachypnoea and possible persistent pulmonary hypertension of the newborn. Serious respiratory morbidity was defined as that requiring treatment for three or more days with continuous oxygen supplementation, nasal continuous positive airway pressure, or any period of mechanical ventilation.

- The reported data concerning the frequency and severity of respiratory complications were compared between both studied groups and was stratified according to the maternal constitutional factors including age categorized as younger or older than 35 years and body mass index (BMI), categorized as overweight $(\sim 25-<30 \mathrm{~kg} / \mathrm{m} 2)$ or obese (>30- $\mathrm{kg} / \mathrm{m} 2)$.

- The attending pediatrician, who was blind to neonates in either group was responsible for assessment of all 
neonates first by Apgar score and then by signs of respiratory distress: cyanosis, grunting, inspiratory stridor, nasal flaring and tachypnea, retraction in subcostal, intercostal, and supracostal spaces with possible specific radiological features. Admission to NICU, was assessed in both groups in whom respiratory distress was graded according to its severity.

- All other possible complications were looked for as pneumonia, perinatal death (within first $24 \mathrm{~h}$ ) and if mechanical ventilation is needed.

\section{$\underline{\text { Statistical analysis }}$}

The data were coded, entered and processed on computer using Statistical Package of Social Science (SPSS) (version 21).The results were represented in tabular and diagrammatic forms then interpreted. Mean, standard deviation, range, frequency, and percentage were used as descriptive statistics. The following tests were done: Chi-Square test $\mathrm{X}^{2}$, Student's t-test. $\mathrm{P}$ value was considered significant as the following: $* \mathrm{P} \leq 0.05$ : Significant

\section{Results}

There is no statistically significant difference between group A and group B regarding maternal age, BMI, gravidity and mean number of previous C.S, $\mathrm{P}>0.05$ (Table 1).
There is no statistically significant difference $(p>0.05)$ between group $\mathrm{A}$ and Group B regarding birth weight and gestational age (Table 2).

The mean value of Apgar scores at 1 minute was statistically $(p<0.05)$ higher among Group A than Group B. Mean value of Apgar scores at 5 minutes was statistically $(p<0.05)$ higher among Group A than Group B (Table 3).

The percentage of the TTN was statistically lower $(p<0.05)$ among Group A than Group B (Table 4).

There is statistically significant $(p<0.05)$ less number of neonates who needed admission to NICU in Group A than in neonates of Group B (Table 5).

There is no statistically significant difference $(p>0.05)$ between neonates of Group A (Steroid Group) and neonates of Group B (Control Group) regarding neonatal need for mechanical ventilation (Table 6).

There is statistically significant lower $(p<0.05)$ numbers of neonates in Group A than in Group B regarding neonatal need for CPAP (Table 7).

The percentage of the grades of respiratory distress was statistically lower $(p<0.05)$ among Group A than Group B (Table 8). 
Table (1): Comparison Between Group A (Steroid Group) and Group B (Control Group) Regarding Maternal Constitutional Data.

\begin{tabular}{|c|c|c|c|c|c|}
\hline & & & Group A & Group B & P. value \\
\hline \multicolumn{2}{|c|}{ Maternal Age (weeks) } & $\mathrm{Mean} \pm \mathrm{SD}$ & $25.2 \pm 1.2$ & $24.9 \pm .9$ & $>0.05$ \\
\hline \multicolumn{2}{|l|}{ BMI } & Mean+SD & $28.9 \pm .8$ & $29.1 \pm .7$ & $>0.05$ \\
\hline \multirow{6}{*}{ BMI categories } & \multirow{2}{*}{ Normal } & No. & 158 & 157 & \multirow{6}{*}{$>0.05$} \\
\hline & & $\%$ & 79 & 78.5 & \\
\hline & \multirow{2}{*}{ Over weigh } & No. & 32 & 34 & \\
\hline & & $\%$ & 16 & 17 & \\
\hline & \multirow{2}{*}{ Obese } & No. & 10 & 9 & \\
\hline & & $\%$ & 5 & 4.5 & \\
\hline \multicolumn{2}{|l|}{ Gravidity } & $\mathrm{Mean} \pm \mathrm{SD}$ & $2.9 \pm .1$ & $2.8 \pm .2$ & $>0.05$ \\
\hline \multirow{2}{*}{\multicolumn{2}{|c|}{ Mean number of Previous C.S }} & Mean+SD & & & $>0.05$ \\
\hline & & & $2.3 \pm .09$ & $2.1 \pm .08$ & \\
\hline
\end{tabular}

Table (2): Comparison Between Group A (Steroid Group) and Group B (Control Group) Regarding Neonatal Constitutional Data.

\begin{tabular}{lllll}
\hline & & Group A & Group B & P. value \\
\hline Birth weight( in Kgm) & Mean+SD & $2.9 \pm .9$ & $3 \pm .8$ & $>0.05$ \\
Gestational age (in weeks) & Mean+SD & $38.2 \pm 1$ & $38 \pm .7$ & $>0.05$ \\
\hline
\end{tabular}

Table (3): Comparison Between neonates of Group A (Steroid Group) and neonates of Group B (Control Group) Regarding neonatal Apgar scores at 1 and 5 minutes

\begin{tabular}{|c|c|c|c|c|}
\hline & & Group A & Group B & P. value \\
\hline Apgar scores at 1 minutes & Mean \pm SD & $8.7 \pm .9$ & $6.8 \pm .5$ & $<.05$ \\
\hline Apgar scores at 5 minutes & Mean \pm SD & $8.9 \pm .1$ & $8.2 \pm .4$ & $<.05$ \\
\hline
\end{tabular}


Table (4): Comparison Between neonates of Group A (Steroid Group) and neonates of Group B (Control Group) Regarding neonatal Transient Tachypnea of the Newborn (TTN).

\begin{tabular}{|c|c|c|c|c|c|}
\hline & & & Group A & Group B & P. value \\
\hline \multirow{4}{*}{ TTN } & & No. & 12 & 25 & \multirow{4}{*}{$<.05$} \\
\hline & Yes & $\%$ & 6 & 12.5 & \\
\hline & \multirow{2}{*}{ No } & No. & 188 & 175 & \\
\hline & & $\%$ & 94 & 87.5 & \\
\hline
\end{tabular}

Table (5): Comparison Between neonates of Group A (Steroid Group) and neonates of Group B (Control Group) Regarding neonatal Admission to NICU.

\begin{tabular}{llllll}
\hline & & & Group A & Group B & P. value \\
\hline \multirow{2}{*}{ Admission to NICI } & & No. & 7 & 18 \\
& yes & \% & 3.5 & 9 & $<.05$ \\
& & No. & 193 & 96.5 & 182 \\
\hline
\end{tabular}

Table (6): Comparison Between neonates of Group A (Steroid Group) and neonates of Group B (Control Group) Regarding neonatal need for Mechanical ventilation.

\begin{tabular}{llllll}
\hline & & & Group A & Group B & P. value \\
\hline $\begin{array}{l}\text { Mechanical } \\
\text { ventilation }\end{array}$ & Yes & No. & 0 & 2 & \\
& & 0 & 1 & 198 \\
& No & No. & 200 & 99 & \\
& & $\%$ & 100 & 05 \\
\hline
\end{tabular}

Table (7): Comparison Between neonates of Group A (Steroid Group) and neonates of Group B (Control Group) Regarding neonatal need for continuous positive airway pressure (CPAP).

\begin{tabular}{|c|c|c|c|c|c|}
\hline & & & Group A & Group B & P. value \\
\hline \multirow[t]{4}{*}{ CPAP. } & & No. & 5 & 10 & \multirow{4}{*}{$<.05$} \\
\hline & yes & $\%$ & 2.5 & 5 & \\
\hline & \multirow{2}{*}{ no } & No. & 195 & 190 & \\
\hline & & $\%$ & 97.5 & 95 & \\
\hline
\end{tabular}


Table (8): Comparison Between neonates of Group A (Steroid Group) and neonates of Group B (Control Group) Regarding Grades of Respiratory distress.

\begin{tabular}{|c|c|c|c|c|c|}
\hline & & & Group A & Group B & P. value \\
\hline \multirow{10}{*}{$\begin{array}{l}\text { Respiratory } \\
\text { distress }\end{array}$} & & No. & 189 & 182 & \multirow{10}{*}{$<.05$} \\
\hline & No RD & $\%$ & 94.5 & 91 & \\
\hline & $C_{2}$ & No. & 7 & 10 & \\
\hline & Grade i & $\%$ & 3.5 & 5 & \\
\hline & \multirow{2}{*}{ Grade II } & No. & 2 & 4 & \\
\hline & & $\%$ & 1 & 2 & \\
\hline & \multirow{2}{*}{ Grade III } & No. & 1 & 2 & \\
\hline & & $\%$ & .5 & 1 & \\
\hline & \multirow{2}{*}{ Grade IV } & No. & 1 & 2 & \\
\hline & & $\%$ & 0.5 & 1 & \\
\hline
\end{tabular}

\section{Discussion}

In the current study, there is no statistically significant difference between group $\mathrm{A}$ and group B regarding maternal age, BMI, gravidity and mean number of previous C.S.

In the current study, there is no statistically significant difference between group $\mathrm{A}$ and group $\mathrm{B}$ regarding birth weight and gestational age.

This agrees with Salem et al., (1) in a casecontrol study aiming to evaluate the effect of dexamethasone administration 48 hours before elective cesarean section (CS) at term on neonatal respiratory morbidity, in Sohag University Hospital ( $\mathrm{N}=246)$. The control group included women who did not receive dexamethasone before CS during the same period of the study $(\mathrm{N}=275)$. They revealed that, there were no significant differences between the two groups with regard to neonatal birth weight and gender.

This agrees also with Morad et al., ${ }^{(9)}$ who aimed to evaluate the effect of prenatal dexamethasone administration on the frequency and severity of neonatal respiratory complications of elective cesarean section (CS) around 37 weeks gestational age (GA) in a prospective randomized trial at departments of Gynecology and Obstetrics, and Pediatrics, Faculty of Medicine, Benha University. The study included 610 multigravida women assigned for repeated CS around 37 weeks. Parturient were randomly divided into two equal groups: 
Group A (Study group) assigned to receive two intramuscular dexamethasone injections (12 mg each) 12-hours apart and 12 hours prior to elective CS. Group B (Control group) received no dexamethasone priming. They found that, there were no significant differences between the two groups with regard to neonatal birth weight and gender.

This study showed that the mean value of Apgar scores at 1 minute was higher among group A than group B. Moreover, mean value of Apgar scores at 5 minutes was higher among group A than group B.

This agrees with Salem et al., ${ }^{(1)}$ who found that, there were significantly higher Apgar scores at 1 and 5 minutes after delivery in the study group (Group I) ( $\mathrm{p}=0.0001$ and 0.011 respectively).

The present study showed that, TTN was lower among group A 12(6\%) than group B $25(12.5 \%)$.

The present study agreed with GyamfiBannerman et al., (10) who confirmed that administration of dexamethasone to women significantly reduced the rate of TTN and surfactant use.

This agrees also with Morad et al., ${ }^{(9)}$ who reported transient tachypnoea of the newborn in 39 neonates; 28 neonates in group B (Control group) and 11 neonates in group A (Study group).
This also agrees with Sotiriadis et al., ${ }^{(2)}$ who aimed to assess the effect of prophylactic corticosteroid administration before elective caesarean section at term. They included four trials (3956 women and 3893 neonates), that were compared to the control group who received a saline placebo or treatment as usual. Prophylactic antenatal corticosteroid administration appeared to decrease the risk of transient tachypnoea of the neonate (TTN).

An earlier study done by Morrison et al., (11) reported that the incidence of respiratory morbidity was significantly higher in women delivered by elective CS (35.5/1000) compared with CS during labor (12.2/1000) $(p<0.001)$. They found that prophylactic use of betamethasone in that group of women before elective CS at term reduces the risk of respiratory morbidity.

Contrary to our findings, another study by Nada et al., ${ }^{(12)}$ reported that, prophylactic dexamethasone did not significantly reduce the incidence of RDS or the need for mechanical ventilation in the study and control groups ( $p=0.103,0.127$ respectively).

Contrary to our findings, a randomized controlled study by Nabhan et al., (13) in Egypt of 123 women showed that prophylactic administration of 4 doses of 12 mg dexamethasone 48 hours before elective CS performed at gestational age between 3437 weeks was not superior to no prophylaxis regarding TTN ( $p=0.612)$. The difference in 
the dexamethasone dose and the gestational age of the study participants, as well as the larger sample size in the current study, may be behind the differences with our results.

The present study showed that, there is statistically significant difference between group A 7 (3.5\%) and group B 18 (9\%) regarding admission to NICU.

In 2015, a large RCT was conducted in Egypt by Nada et al., (12) to determine whether prophylactic dexamethasone in a dose of 8 $\mathrm{mg} / 12$ hours for 3 doses over 48 hours before elective CS at term would decrease the neonatal respiratory morbidity. They found that the NICU admission rate was significantly lower in the dexamethasone group compared with the control group (3.1\% versus $6.7 \%$, respectively; $p=0.003$ ).

This also agrees with Salem et al., ${ }^{(1)}$ who found that, the number of neonates admitted to NICU was significantly higher in the control group than the study group ( $p=0.003$ ).

This also agrees with Stutchfield et al., (6) who reported that, betamethasone given immediately before elective CS at term reduces respiratory distress and admission to NICU.

This also agrees with Sotiriadis et al., ${ }^{(2)}$ and Guilherme et al., (14) who found that, prophylactic betamethasone appeared to significantly decrease the risk of admission to NICU for respiratory morbidity.
Contrary to our findings, ${ }^{(13)}$ admission to NICU was not statistically significant between two groups $(p=0.535)$. This is explained by the difference in the dexamethasone dose and the gestational age of the study participants, as well as the larger sample size in the current study.

The present study showed that, there is no statistically significant difference between neonates of group A (Steroid group) and neonates of group B (Control group) regarding neonatal need for mechanical ventilation.

This agrees with Sotiriadis et al., (2) who concluded that there was no significant difference between women who received betamethasone as compared to those who did not with regard to the need for mechanical ventilation.

This disagrees with Salem et al., (1) who found that, the number of neonates who needed mechanical ventilation after birth due to respiratory complications was higher in the control group $(p=0.027)$.

Contrary to our findings, in 2011, a study was conducted in Brazil by Porto et al., ${ }^{(15)}$ who found that, 273 women who were given betamethasone at the daily dose of $12 \mathrm{mg}$ for 2 days did not reduce the incidence of respiratory disorders in newborn infants. Again, their results were different from our study, though it is of note that this study had a 
different methodology than ours. Specifically, they included all deliveries between 34-36 weeks whether born vaginally or by CS; additionally, a different type of corticosteroid was used.

The present study showed that, there is statistically significant higher numbers of neonates in group $\mathrm{A}$ than in group $\mathrm{B}$ regarding neonatal need for CPAP.

This agrees with Salem et al., (1) who found that, the number of neonates who needed CPAP after birth due to respiratory complications was higher in the control group $(p=0.0001)$.

This also agrees with a retrospective cohort study of 167 women after 34 weeks of gestation found that betamethasone therapy was associated independently with improved neonatal outcome. Authors recommended its use when fetal lung immaturity is documented $^{(16)}$.

Contrary to our findings, a study of 362 neonates born at 34 weeks of gestation or more found that even if immature fetal lung indices were detected, administration of antenatal corticosteroids did not reduce respiratory morbidity in neonates born at 34 weeks of gestation or more ${ }^{(17)}$.

\section{Conclusion:}

Prophylactic intramuscular injection of $12 \mathrm{mg}$ dexamethasone 12 hours apart, 24 hours before elective CS at gestational age of 37 to 39 weeks can reduce both neonatal respiratory morbidity and admission to Neonatal Intensive Care Unit.

\section{References:}

1. Salem MN, Abbas AM and Ashry M. Dexamethasone for the prevention of neonatal respiratory morbidity before elective cesarean section at term. ProcObstet Gynecol. 2016;6(3): 2 10 .

2. Sotiriadis A, Makrydimas G, Papatheodorou S,

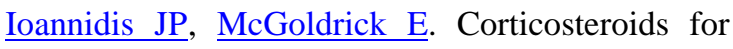
preventing neonatal respiratory morbidity after elective caesarean section at term. Cochrane Database Syst Rev. 3 2018;8:CD006614.

Van den Berg A, van Elburg RM, van Geijn HP, and Fetter, W.P. Neonatal respiratory morbidity following elective caesarean section in term infants. A 5-year retrospective study and a review of the literature. Eur J ObstetGynecolReprod Biol. 2001;98(1):9-13.

3. Miracle X, Di Renzo GC, Stark A, Fanaroff A, Carbonell-Estrany $X$, Saling E; Coordinators Of World Association of Perinatal Medicine Prematurity Working Group. Guideline for the use of antenatal corticosteroids for fetal maturation. J Perinat Med. 2008;36(3):191-6.

4. Marciniak B, Patro-Małysza J, PoniedziałekCzajkowska E, Kimber-Trojnar Z, LeszczyńskaGorzelak B, Oleszczuk J. Glucocorticoids in pregnancy. Curr Pharm Biotechnol. May 2011;12(5):750-7. 
5. Stutchfield P, Whitaker R and Russell I; Antenatal Steroids for Term Elective Caesarean Section (ASTECS) Research Team: Antenatal betamethasone and incidence of neonatal respiratory distress after elective caesarean section: pragmatic randomized trial. BMJ. 2005; 331(7518):662.

Mwansa-Kambafwile J, Cousens S, Hansen T Lawn JE. Antenatal steroids in preterm labour for the prevention of neonatal deaths due to complications of preterm birth. Int $\mathrm{J}$ Epidemiol. 2010;39 (1);122-33.

6. Jain L and Dudell GG. Respiratory transition in infants delivered by cesarean section. SeminPerinatol. Oct 2006;30(5):296-304.

7. Morad AW, Shedid AA and Assar EH.: Prophylactic Dexamethasone ameliorates Neonatal Respiratory Complications after Elective Cesarean Section: A comparative Study Tanta Medical Journal. (2010); (38), 197-207.

8. Gyamfi-Bannerman, C., Thom, E. A., Blackwell, S. C., Tita, A. T., Reddy, U. M., Saade, G. R., NICHD Maternal-Fetal Medicine Units Network (2016). Antenatal Betamethasone for Women at Risk for Late Preterm Delivery. The New England journal of medicine, 374(14), 1311-1320.

9. Morrison JJ, Rennie JM and Milton PJ. Neonatal respiratory morbidity and mode of delivery at term: influence of timing of elective caesarean section. $\mathrm{Br} \quad \mathrm{J}$ ObstetGynaecol 1995;102:101-6.
10. Nada AM, Shafeek MM, El Maraghy MA, Nageeb AH, Salah El Din AS, Awad MH. Antenatal corticosteroid administration before elective caesarean section at term to prevent neonatal respiratory morbidity: a randomized controlled trial. Eur J ObstetGynecolReprod Biol. 2016;199:88-91

11. Nabhan A, Al-Helaly A and Ramadan A. Prophylactic antenatal corticosteroid before elective cesarean delivery at or near term to improve perinatal outcome. Med J Cairo Univ. Mar 2014;82(1):25-8.

12. Guilherme R and Rotten D; CEGORIF Group: Betamethasone before elective caesarean section at term: a survey of practice in France. Eur $\mathbf{J}$ ObstetGynecolReprod Biol. 2010; 150(1):104.

13. Porto AM, Coutinho IC, Correia JB, Amorim MM. Effectiveness of antenatal corticosteroids in reducing respiratory disorders in late preterm infants: randomised clinical trial. BMJ. 2011;342:d1696.

14. Yinon Y., Haas J., Mazaki-Tovi S., Lapidot N, Mazkereth R, Hourvitz A. et al.: Should patients with documented fetal lung immaturity after 34 weeks of gestation be treated with steroids? Am. J. Obstet. Gynecol., 2012. 207 (3): 222. 1-4.

15. Kamath-Rayne, B. D., DeFranco, E. A., and Marcotte, M. P. Antenatal steroids for treatment of fetal lung immaturity after 34 weeks of gestation: an evaluation of neonatal outcomes. Obstetrics and gynecology, (2012). 119(5), 909-16.

To cite this article: Ahmed M. Elewa, Ahmed S. Saad, Ahmed S. Soliman, Sally A. Al Saber. Does Corticosteroids Administration after 37 Weeks for Elective Lower Segment Cesarean Section Reduce Neonatal Respiratory Morbidity? a Randomized Controlled Trial. BMFJ 2020; 37(3):607-618, DOI: 10.21608/bmfj.2020.18189.1130 